
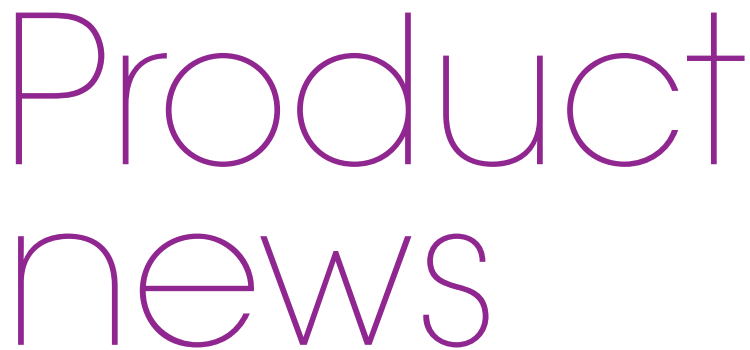

Product news is provided as a service to readers using text and images from

the manufacturer, supplier or distributor and does not imply endorsement

by BDJ Team. Normal and prudent research should be exercised before

purchase or use of any product mentioned.

\section{RESULTS TO BUILD A REPUTATION ON}

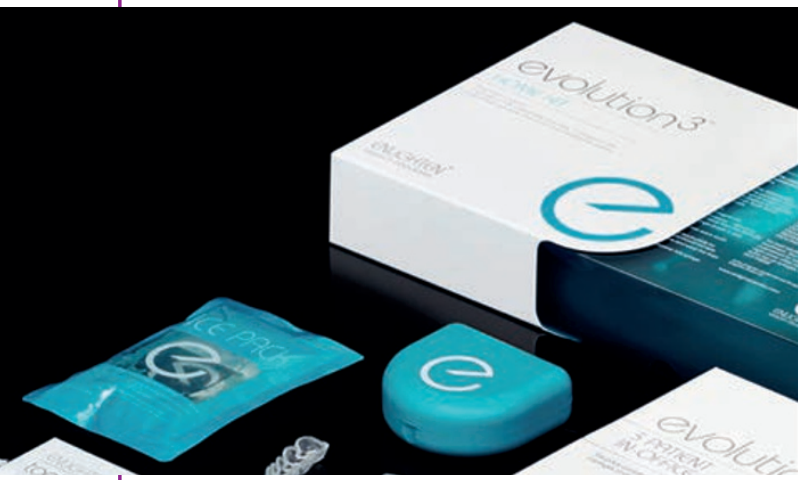

experience any sensitivity, Enlighten also provides desensitising swabs and special Tooth Serum toothpaste to ensure patients are as comfortable as possible throughout the treatment.

This attention to detail can make all the difference in your practice. By using Enlighten products, your patients will know that you are providing them with the very best. They know that at the end of their treatment, they will have the smile
If you want to acquire a reputation for providing the best tooth whitening at your practice, then you should be using products from Enlighten.

With a $98 \%$ success rate to VITA B1, Enlighten products are the profession's only option for a guaranteed whiter smile.

Demonstrably safe, Enlighten products use materials that have been in use in dentistry for over 100 years - however, if patients do they have always wanted - and if you have the reputation for being able to provide this kind of service, there will be no end to the benefits!

To offer your patients the very best options possible, offer them Enlighten whitening.

For more information, visit www. enlightensmiles.com, email info@ enlightensmiles.com or call the team on 0207 4243270 .

\section{HOW MANY OF YOUR PATIENTS CLEAN INTERDENTALLY?}

Oral care experts Tandex offer the FLEXI and PROXI interdental brushes. Not only do they look great, but all your patients will find them easy to master.

The FLEXI has an ergonomic, flexible grip to access all the tricky spaces in the mouth. In nine sizes, there will be a brush suitable to gently and efficiently clean even the smallest gaps. The PROXI has a unique patented design with an enclosed metal tip to avoid any trauma to soft tissue. In six sizes, it can be used alongside the FLEXI for optimum hygiene.

Both the FLEXI and PROXI should be used with TANDEX GEL, which is both non-abrasive and clinically proven to be highly effective.

The brushes and gel are just part of a range from Tandex. With 85 years' experience producing quality products, your patients will find Tandex the perfect companion to their daily oral health routine.

For efficient cleaning in between appointments, recommend Tandex. For more information on Tandex's range of products, visit www.tandex.dk.

\section{FOR WATER FLOSSING ON THE GO}

From a long line of outstanding Waterpik Water Flossers comes the brand new Waterpik Cordless Advanced.

Waterpik created the Cordless Advanced Water Flosser to be its best and most innovative cordless Water Flosser yet. It's perfect for people on-the-go or those who want to water floss, but don't have the space for a full-sized unit.

Featuring no cables and a state-of-the-art magnetic charging system complete with micro-processor controls for longer battery life, rapid charge and global voltage, the new model with extra-quiet design makes interdental cleaning hassle free.

What's more, the innovative design offers improved tip rotation for easier access to all areas of the mouth. Plus, with complete waterproof casing, the Waterpik Cordless Advanced is $100 \%$ waterproof and therefore can even be used in the shower for added convenience.

Waterpik Water Flossers have been proven safe and effective for all patients, including those with braces, implants, crowns, bridges and diabetes. ${ }^{1,2}$ The latest model is no exception, and with easy touch electronic controls and three pressure settings, patients can now customise their experience for the ultimate clean and optimum comfort.

Find out today how your patients could benefit from everything this exceptional device can offer by contacting the friendly and helpful team at Waterpik International, Inc.

For more information on Waterpik International, Inc. visit www.waterpik.co.uk. Waterpik products are available on Amazon, in Boots, Costco UK and Superdrug stores across the UK and Ireland.

1. Jolkovsky D L, Lyle D M. Safety of a water flosser: a literature review. Compend Contin Educ Dent 2015; 36: 146-149.

2. Lyle D M. Risk

assessment a key to periodontal health promotion and disease prevention. Compend Contin Educ Dent 2014; 35: 392-397.

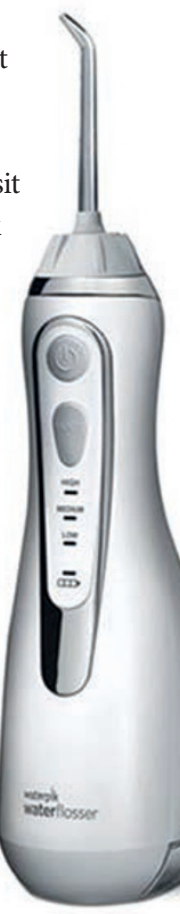

